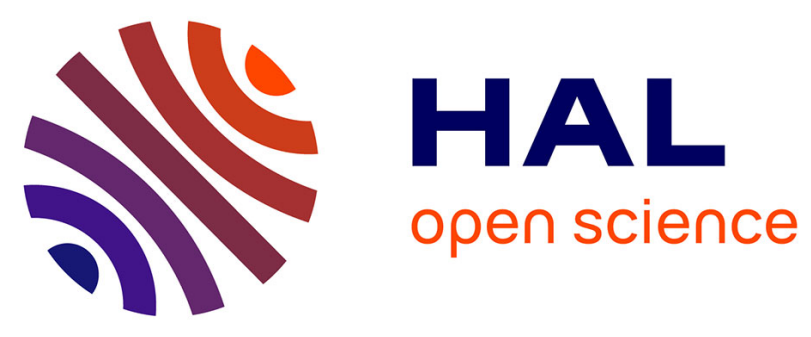

\title{
Smartphone-Based Gait Measurement Application for Exercise and Its Effects on the Lifestyle of Senior Citizens
}

\author{
Takahiro Miura, Ken-Ichiro Yabu, Atsushi Hiyama, Noriko Inamura, \\ Michitaka Hirose, Tohru Ifukube
}

\section{To cite this version:}

Takahiro Miura, Ken-Ichiro Yabu, Atsushi Hiyama, Noriko Inamura, Michitaka Hirose, et al.. Smartphone-Based Gait Measurement Application for Exercise and Its Effects on the Lifestyle of Senior Citizens. 15th Human-Computer Interaction (INTERACT), Sep 2015, Bamberg, Germany. pp.80-98, 10.1007/978-3-319-22698-9_7 . hal-01609403

\section{HAL Id: hal-01609403 https://hal.inria.fr/hal-01609403}

Submitted on 3 Oct 2017

HAL is a multi-disciplinary open access archive for the deposit and dissemination of scientific research documents, whether they are published or not. The documents may come from teaching and research institutions in France or abroad, or from public or private research centers.
L'archive ouverte pluridisciplinaire HAL, est destinée au dépôt et à la diffusion de documents scientifiques de niveau recherche, publiés ou non, émanant des établissements d'enseignement et de recherche français ou étrangers, des laboratoires publics ou privés.

\section{(c)(1)}

Distributed under a Creative Commons Attribution| 4.0 International License 


\title{
Smartphone-based gait measurement application for exercise and its effects on the lifestyle of senior citizens
}

\author{
Takahiro Miura ${ }^{1,2}$, Ken-ichiro Yabu $^{1}$, Atsushi Hiyam a ${ }^{2}$ \\ Noriko Inamura ${ }^{3}$, Michitaka Hirose ${ }^{2}$, and Tohru Ifukube ${ }^{1}$ \\ 1 Institute of Gerontology, the University of Tokyo, \\ 7-3-1 Hongo, Bunky o-ku, Tokyo 113-8656, Japan, \\ \{miu@, yabu@human, ifukube@ human\}.iog.u-tokyo.ac.jp \\ 2 Graduate School of Information Science and Technology, the University of Tokyo, \\ 7-3-1 Hongo, Bunky o-ku, Tokyo 113-8656, Japan, \\ \{miu, atsushi, hirose\}@cyber.t.u-tokyo.ac.jp \\ 3 Urban Design Center Kashiwa-no-ha(UDC K), \\ 178-4 Wakashiba, Kashiwa, Chiba 227-0871, Japan. inamura@ udck.jp
}

\begin{abstract}
Population aging leads to more expensive social security and medical care in a society. In order to minimize national expenditure dedicated to providing support to the elderly, it is necessary to reduce the cost of treatment. Current prophylactic approaches mainly include training programs tailored towards seniors, who may be assisted by caregivers, for wellness maintenance and enhancement. However, these approaches are mainly administered by volunteers, who are often overburdened because of labor shortages. It is thus necessary to design and implement a system that enables seniors to maintain and improve their health by themselves. In this study, we propose and test a smartphone-based gait measurement application. Our results indicate that the mobile application can help motivate seniors to walk more regularly and improve their walking ability. Moreover, we found in our experiments that since our application helped improve our senior subjects' phy sical fitness, some of them became interested in participating in social activities and using new technologies as a consequence.
\end{abstract}

Keywords: Seniors; smartphones; walking; changes in attitudes.

\section{Introduction}

Population aging is among the most critical issues in the world today, particularly in developed countries. It causes reduced domestic productivity and increased expenditure on social security and medical care. In Japan, the population aging rate was $24.1 \%$ in 2013 [14], and has been predicted to be as high as $40.5 \%$ by 2055 [28]. Similarly, the ratio of the young to the elderly in Japan was 2.81 in 2009 , and is predicted to be 1.26 by 2055 [28]. It is thus becoming increasingly difficult to continue with the conventional welfare and social security model in a situation where multiple young citizens support one senior [36, 49].

The cost of national health care can be minimized by reducing medical expenses and increasing expenditure on preventive healthcare, especially with regard to longterm chronic diseases and sudden serious injuries [36]. Concrete prevention strategies include encouraging seniors to maintain and improve their health by themselves, often with support from caregivers. Numerous measures to quantify the state of the health of senior citizens have been proposed in order to support activities among them that are conducive to health maintenance and enhancement. To this end, medical organizations and research institutes regularly organize short-term group exercise courses and 
individual physical training for seniors. However, the regularity of the physical exercise depends on seniors themselves and on the support at their disposal. Effective and reasonable support methodologies for the daily activities of seniors have not yet been developed [12]. Several monitoring systems have been developed to address sudden contingencies among seniors, such as falls as well as acute heart attacks and brain aneurisms. Nevertheless, these activity measurement technologies primarily help monitor seniors' activities in their homes. Monitoring systems need a function to store and analyze seniors' outdoor activities in order to offer more effective assistance for their daily exercise. In particular with regard to walking, not only should such systems measure the user's walking distance, time taken, and the number of steps taken, but also walking velocity, which is closely related to muscle strength [11], as well as balance $[37,50]$.

In recent times, progress in mobile technologies, such as the development of smartphones, has provided highly functional applications that were hitherto available only on personal computers [44]. Mobile devices nowadays contain numerous sensors, including acceleration sensors and location sensors based on global positioning systems (GPS), and some mobile applications make interesting use of these sensors. In particular, these mobile applications can execute measurement functions with or without external sensors, e.g., measurement functions for the user's activity and physical condition, and support software designed for workouts, including aerobic exercises and progressive resistance training. These applications, if conveniently usable by seniors, would help seniors maintain and improve their health, and take advantage of several services geared toward improving their quality of life. Consequently, we assume that these mobile applications likely encourage seniors not only to maintain their health, but also to participate in social activities, such as community workshops and volunteer engagements, because of stable health. However, few studies have researched the measurement of gait parameters of seniors while walking through smartphones and analyzed factors that promote active lives among senior citizens. This is due to complications related to controlling the measurement conditions and long-term studies involving seniors.

In order to help senior citizens maintain their daily exercise schedule, improve their health, and to allow their caregivers to monitor their physical condition, we propose and test a smartphone-based gait measurement application to monitor daily walks taken by senior citizens. We do not test cases involving mobile applications with external devices, such as Fitbit or Jawbone, because our preliminary interviews with the senior subjects of our experiments indicated that they desired a mobile application that does not require external devices because they feared losing them. Moreover, they indicated that while they did not mind carrying their mobile devices, they were not used to carrying external devices with them, and hence found the idea uncomfortable.

Our research questions are as follows:

Q1. Can the walk measurement application on smartphones help seniors maintain and promote their physical performance, including walking ability?

Q2. What kinds of side effects does the continued use of the application have for seniors, if any? What is the mechanism, such as consciousness change interactions, of these side effects? 


\section{Related work}

Numerous studies have been conducted on helping seniors maintain and improve their physical fitness. These are classified broadly into two categories: analytic, diagnostic studies of seniors' gait as well as related exercise methods, and support systems for monitoring (and self-monitoring) their bodies and related neurological states. In this paper, we mainly focus on the latter.

\subsection{Walking as an exercise for seniors}

Since walking is one of the easiest regular exercises for seniors, much research has been conducted to analyze walking among seniors and related concepts. Several studies have proposed that seniors maintain muscle strength in order to prevent pelvic girdle weakness. Brisk walking has been recently recommended by many research groups $[18,40]$. For a more active method to prevent adjustable exercise stress, Shimada et al. developed a treadmill-based walking exercise system [43]. Fiatarone et al. and Inaba et al. reported that heavy resistance training of muscles of the lower limbs has significant beneficial effects on muscle size in frail elderly people as well as healthy adults [19,27]. Fiatarone et al. also indicated that seniors effectively improve muscle ability when they exercise based on progressive resistance training and receive appropriate nutritional supplements [20,21]. A training method to improve standing balance among seniors proposed by Tanaka et al. used tactile feedback as well as moving auditory stimuli to guide their body sway [48]. Experimental results showed that the system influenced the body sway of elderly participants to a greater degree than that of young participants.

\subsection{Monitoring daily activities and health: Environmental and portable systems}

This category mainly includes mounted or fixed systems attached to an environment, or constituting the entire environment, and portable or wearable systems that can be hand held, or whose sizes do not hinder daily activities of the users [9]. These systems can continually or continuously monitor users' activities or physical condition.

Examples of mounted systems include monitoring systems based on cameras [33, 15] or infrared rays [22,35] installed at the user's home. With regard to studies on houses that can monitor residents' activity or health, the Georgia Tech Aware Home [31] and the Welfare Techno House [29,47] are good examples. These houses can monitor the state of their dwellers' activities, their physiological parameters, and sudden risks of emergency that are detected and calculated by sensors in the house, e.g., in living rooms, bathrooms, etc. The need for a monitoring user interface for elderly people has also been investigated [39].

Portable monitoring systems can be used in special environments as well as in ordinary surroundings. With progress in wearable computing technology, various compact movable activity meters are commercially available these days $[3,7,6]$. These are based on research related to measurement systems using inertial sensor data [41], an algorithm to estimate a user's movement by analyzing the cell signal strength and visibility of the global system for mobile communications (GSM) [10]. Harris et al. reported that these kinds of devices were effective in encouraging user to exercise, based on the results of experiments that involved recording the step counts of a large group of elderly subjects [24]. 


\subsection{Monitoring applications using smartphones}

The widespread use of smartphones [44,53] enables users to monitor their health and physical condition much more easily than before because mobiles devices contain numerous applications that can determine user-related movements by using acceleration and gyro sensors, and GPS. Based on embedded sensors in smartphones, novel selfmonitoring applications for physical and mental conditions have been proposed. For example, Brajdic et al. reported walk-detection methods [13], and Hammerl et al. proposed a semi-automatic personal digital diary [23].

Smartphone-based support applications for exercise and rehabilitation have also been proposed. Spina et al. developed a motion rehabilitation application that guides users in exercising by using auditory feedback [46]. Silva et al. applied embedded acceleration sensors to a dancing game to assess players' risk of fall [45]. Some systems used short messaging service (SMS) and social networking functions to enable users to manage their bodies and mental conditions themselves [30,34]. Some case-specific support applications for monitoring the health of obese people [16], pediatric asthma patients [51], and persons requiring surgical pain therapy [42] have also been proposed. To assist medical staff, Mahmud et al. proposed a decision-making application for midwives [8]. Hurling et al. reported that an automated motivation and action support system implemented on mobiles can help increase and maintain the level of physical activity in healthy adults [26].

\subsection{Issues addressed in this study}

The aforementioned conventional studies analyzed physical conditions mainly in experimental or indoor environments, and helped users maintain their health by prompting them to exercise. However, a few studies have researched regular outdoor workouts, including walking and hiking, to maintain and improve health among senior citizens. It is true that traditional pedometers can help motivate walkers to continue exercising, but similar and advanced functions should be provided for smartphones with senior-friendly user interfaces to provide them opportunities to actively participate in social activities. We assume that our proposed application can enable seniors to not only maintain and improve their health, but also to find their motivation in life and improve their quality of life (QoL). However, these aspects were not evaluated in our clinical sites. We limit our research to answering the two questions posed by developing an application to monitor walking for smartphones, and then assessing the effects of this system on seniors.

\section{Proposed system}

\subsection{System overview}

We implemented an application to measure walking characteristics based on sensors embedded in a representative smartphone: the Apple iPhone 4S. Smartphones with our application installed on them were distributed among seniors who were participants in our experiment. The user interface for this application was brushed up three times after a preliminary evaluation by a small group of participants who were senior citizens. They were then asked to use the application to log the details of their outdoor walking 


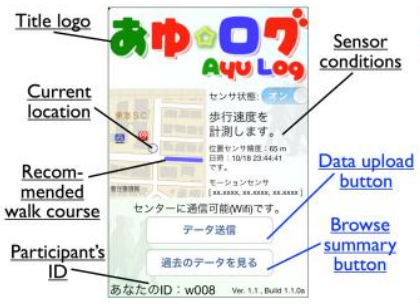

A) Home view

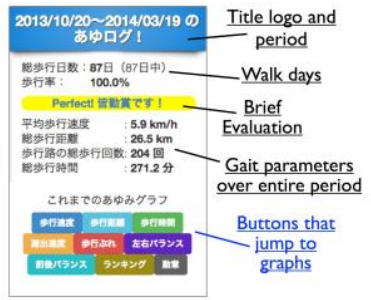

B) Summary view

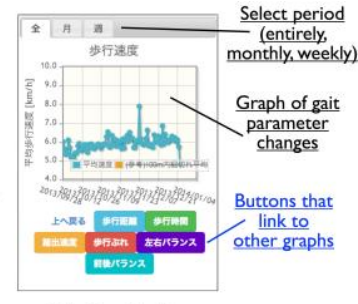

C) Graph view

Fig. 1. The user interface of the proposed exercise measurement application for seniors. The characters in the views are Japanese.

exercises. The walk-related parameters of each participant were calculated by a server once the $\log$ s were uploaded to it. These estimated gait parameters, including walking distance, time taken, and velocity, can be checked through our application.

In this procedure, the application recorded the logs of the embedded acceleration and gyro sensors and acquired location information from the GPS. The server calculated the walking distance, the time taken, and the velocity using the location information, and determined each participant's balance functions, body sways, and the number of steps taken using the acceleration and gyro sensors and referring to studies by Zheng et al., Arai et al., and Inaba et al. [11, 27, 52].

\subsection{Interfaces}

The views offered by our application named AyuLog (which means walk logger in Japanese) and shown in Fig. 1, include home, summary, and graph views that handle functions that log the sensor values, display walk summaries for the entire period of use of the application, and show detailed results. The design of these views, including button and font sizes, was developed by consulting the Apple iOS Human Interface Guidelines and a guideline for seniors proposed by Kobayashi et al. [1,32]. To avoid confusion, the interface can be operated only by tapping a few buttons. We instituted this mechanism based on the results of three preliminary evaluation experiments involving a small group of senior participants. In this evaluation, which was based on a user-centered design (UCD) approach, the participants were asked to manipulate entire views of the application and then answer questions related to problems that they encountered as well as their suggestions for improvement, such as those regarding button size and allocations, and the method of checking the graphs. As a result, the number of buttons in the home and summary views was reduced following the preliminary evaluation, and the graph view was altered to use simple interactions to check us ers' monthly, weekly, and overall results.

When the home view shown in the left part of Fig. 1 was activated, the application stored sensor logs and displayed instantaneous sensor values. The sampling frequencies of the GPS and the acceleration/gyro sensors were set to $1 \mathrm{~Hz}$ and $10 \mathrm{~Hz}$, respectively. When an experimenter sets recommended walking courses, this application can display these courses in deep blue color in the left-middle part of the view. When a user reaches 

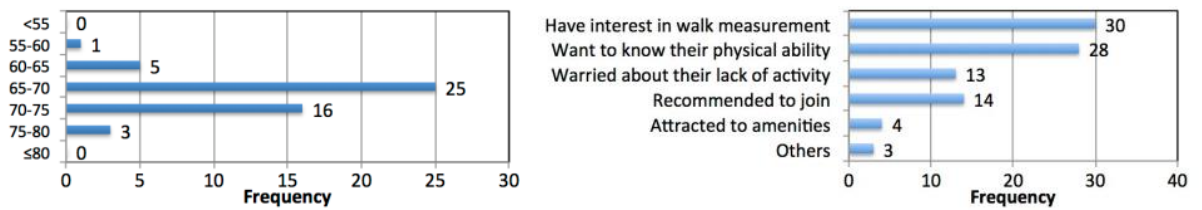

Fig. 2. Left: The age group of the participants. Right: Participants' reasons for joining this experiment. They were allowed to select multiple items as responses.

and enters a course, the application records whether the relevant location is a recommended course. When a user enters the course, the audio guide announces, "You are in the recommended course." As a user exits a course, the audio guide informs him/her, "You have exited the recommended course." This view also has buttons to upload stored logs and browse user exercise results by accessing the server.

The summary and graph views shown in the middle and right parts of Fig. 1, respectively, inform users about the results of their exercise. These views are web views returned from the calculation server, and show the estimated gait parameters mentioned in Section 3.1 over the entire period of use of the application as well as periodic results. We used a server with Ubuntu Linux 12.04 operating system (OS) that can calculate and display the results, with the back end and front end coded in PHP, Javascript, Cascading Style Sheets (CSS), and especially jqPlot [4], jQuery mobile[5], and Twitter Bootstrap[2].

\section{Evaluation}

We carried out a three-month evaluation of the proposed system. Approval for our experiment was obtained from the Office for Life Science Research Ethics and Safety at our institute, and the consent of all participants was obtained. This evaluation was conducted from September to December, 2013 (87 days).

\subsection{Participants}

Fifty retired seniors citizens, whose age distribution is shown in the left part of Fig. 2, participated in this experiment. They comprised 30 males (mean age 69.7, \pm 3.2 years) and 20 females (mean age $66.0 \pm 4.1$ years). All participants were recruited through an advertisement by a local volunteer group. Reasons cited in the right part of Fig. 2 suggest that most participants joined the experiment because they were interested in learning more about their own physical condition. A total of $42.2 \%$ and $48.9 \%$ of them had a habit to walk outside almost every day and a few times a week, respectively.

As shown in the left part of Fig. 3, several participants had previously used information and communication technologies (ICTs) such as personal computers but had little to no experience of smartphones and tablets. However, as shown in the right part of Fig. 3, almost half of them wanted to use these touchscreen devices.

\subsection{Method}

Experimental procedure: We gave a smartphone, with our application installed on it, to each participant in the experiment. We explained to them the kinds of parameters that the application calculated and displayed in order to observe the effects of the 


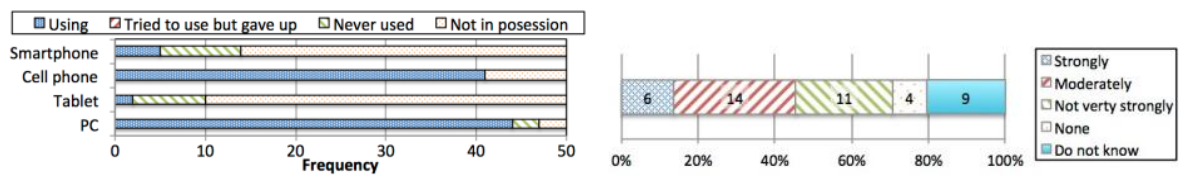

Fig. 3. Left: Participants' experience of use of ICTs. Right: Participants' willingness to use touchscreen devices.

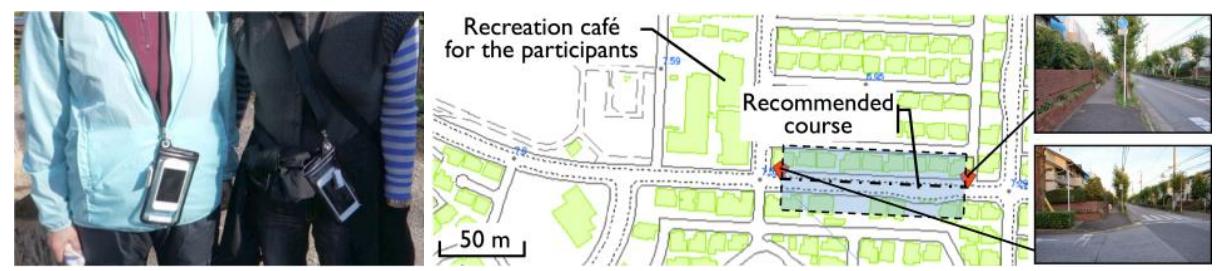

Fig. 4. Left: User wearing the device. The device is slung around the user's neck and fitted inside the user's jacket. Right: A brief overview of the recommended walking course.

exercise on them and to review the details of their past physical activity. We then instructed them on how to use the application, which required that each participant record his/her physical detail, including height, weight, and body fat percentage. Following this, they were asked to use the application for three months by attaching the device inside their jackets after having hung it around the neck, as shown in the left part of Fig. 4. This instruction was given because some seniors, who participated in the preliminary evaluation, reported feeling a sense of ease while walking with a smartphone in a strapped case to prevent it from falling. They were then asked to regularly walk the recommended course during this period, as shown in the right part of Fig. 4. The course was approximately 100 meters long (111.5 m, strictly), was flat, and was located on a quiet street in a residential district of the participants to provide safe walking conditions for the seniors subjects of our experiments. The course also provided suitable conditions for smartphone-embedded sensors to acquire walking-related motion changes. On this course, the horizontal accuracy of location estimation by the GPS was comparatively accurate, i.e., within 5-10 meters (see Section 5.1). This course limitation was set in order not only to secure the participants' privacy and physical safety, but also to adjust measurement conditions for the embedded sensors and develop a reference gait database for the seniors subjects at an outside location for medical usage in the future.

We also held monthly meetings with the participants to discuss problems they might have had in using the application and advised them accordingly. We conducted a few measurements during these meetings to calculate the above-mentioned physicalparameters, mental conditions, and changes in attitudes regarding social activities and novel technologies by interviewing the participants' caregivers and having the participants fill out questionnaires.

Measured items and analysis: We employed height, weight, body fat percentage, skeletal muscle mass, grasping power, and boundary lengths of the thighs and upper arms as physical conditions. These parameters, excluding the boundary lengths, were measured by a Biospace InBody 430 whereas the boundary lengths were measured using a measuring tape. 
The objective of the questionnaire was to collect the following data. These items were originally written in Japanese.

Preliminary survey: Subjective health condition, subject's awareness of his/herhealth, fitness habits, and use of ICTs.

Midterm survey: Subjective health condition, exercise awareness, walking environments, positive and negative effects of application use, and difficulty in using the application.

Post-experiment survey: Subjective health condition, subjects' awareness of own health, fitnes s habits, positive and negative effects of application use, promotional and obstructive factors to continuing exercise, and difficulty in use of and shortcomings of the application.

A few items did not directly relate to maintenance and improvement of physical activity. However, because it is known that some healthy seniors are interested in participating in social activities, we would like to investigate the effects of improvement in physical performance on attitudes to social activities, and to novel things in general. Specific questionnaire items from our study are shown in the labels on the vertical axes in Figures 6-9. Although these items include indirect elements related to physical ability, we wanted to check the range of positive effects of exercise facilitated by the proposed application.

Gait parameters were obtained by using data from the smartphone sensors and GPS $\operatorname{logs}$, which were restricted to records of the recommended course for privacy reasons. These parameters included duration, distance, and velocity of walking based on GPS $\operatorname{logs}$, as well as front-back/right-left body sways and balance based on acceleration $\log$ s. We also checked each participant's access counts to the summary views.

The results of the survey questionnaires were summarized by aggregating participant responses. In the following, we will compare the responses according to the frequency of the items, and will discuss the psychological effects of the application on the participants. In this analysis, the participants were categorized by performance changes in walking velocity based on the effect size of Cohen's $d(|d|<0.2$ : negligible, $|d|<0.5$ : small, $|d|<0.8$ : medium, $|d| \geq 0.8$ : large).

\section{$5 \quad$ Results and discussion}

In this section, we describe the results of our experiments involving GPS-related data and subjects' responses to our questionnaire.

\subsection{Horizontal accuracy of GPS in experimental location}

Before distributing the smartphones, we evaluated the measurement accuracy of the application for the recommended walking course shown in the right part of Fig. 4. In this preliminary evaluation of the 50 smartphones, we measured GPS-related parameters, including horizontal accuracy, occurrence frequency of obtaining the location, and walking distance. The repeat count to go back and forth on the recommended road was six times one way. 
The success rate of the GPS was $97.6 \%$ in the $110-\mathrm{m}$ recommended course. The mean values of horizontal accuracy and estimated walking distance for all devices were $5.8 \mathrm{~m}$ (Standard deviation (SD): $5.7 \mathrm{~m}, 95 \%$ Confidence interval $(\mathrm{CI}): 0.65 \mathrm{~m}$ ) and $109.9 \mathrm{~m}$ (SD: $9.2 \mathrm{~m}, 95 \% \mathrm{CI}: 1.06 \mathrm{~m}$ ), respectively. However, when the statistical values were calculated by each device, the standard deviation was zero for $66 \%$ of the devices whereas $8 \%$ of the devices returned a value over $1.0 \mathrm{~m}$. These results indicated that the horizontal accuracy of GPS location varied among the smartphones. However, disregarding cases where the horizontal accuracy was $60-80 \mathrm{~m}$, the application correctly and consistently estimated the walking distance (e.g., the walking distance was estimated as $110.2 \pm 1.4 \mathrm{~m}$ given $43.9 \pm 26.2 \mathrm{~m}$ horizontal accuracy). This result suggested that even if the horizontal accuracy is not correct, the walking distance can occasionally be correctly estimated when the device obtains a broad location. Thus, because time lags among the clocks of the mobile devices clocks are remarkably small, the proposed application can measure the walking distance and the velocity with a probability of over $97 \%$.

\subsection{Walking days, distance, and velocity}

During the experimental period, the mean distance walked by all participants and the number of days on which they went for walks were $11.5 \mathrm{~km}$ (SD: $4.5 \mathrm{~km}, 95 \% \mathrm{CI}: 1.2$ km, Range: $5.0-27.3 \mathrm{~km}$ ) and 61.1 days (SD: 13.8 days, 95\% CI: 3.8 days, Range: 23 - 87 days), respectively. Regarding their frequency of outside walks, $70.0 \%$ of the participants said that they walked outside almost every day and $28.0 \%$ reported doing so a few times a week. These results suggest that the proposed application helped seniors maintain their walking activity and encouraged it, or at least did not prevent them from continuing it.

The mean walking velocity of the participants was $5.42 \mathrm{~km} / \mathrm{h}(\mathrm{SD}: 0.44 \mathrm{~km} / \mathrm{h}, 95 \%$ CI: $0.12 \mathrm{~km} / \mathrm{h}$, Range: $4.41 \sim 6.33 \mathrm{~km} / \mathrm{h}$ ) for the experimental period. The left figure of Fig. 5 shows the trend of mean walking velocity change for all particip ants. The abscis sa represents part of the experimental periods divided into 10 segments for each participant. We employed this normalized scale because the number of days on which a walk was taken and the distances walked varied among the participants. The figure shows that the walking velocity of the participants significantly improved after the three-tenth partial experimental period walk, and then remained constant until the end of the experimental period (Tukey's honest significant difference (HSD) test). Comments from most participants indicated that they found it helpful and exciting to check the results of their walks, and were motivated to continue their activity as a consequence. As shown in Table 1, the improvement in walking velocity improvement for each participant can be confirmed by the effect size (Cohen's $d$ ) between the one-tenth and ten-tenth experimental periods. These facts indicate that our application contributed to promoting walking among seniors and to increasing their pace.

As shown in the right part of Fig. 5, trends of change in walking velocity varied among the participants. In this graph, we show examples of walking velocity transitions based on effect sizes (Cohen's $d$ ) shown in Table 1. The participants whose effect sizes were large or medium almost monotonically improved their walking velocity, whereas flat curves resulted in cases involving the participants whose effect sizes were small or 

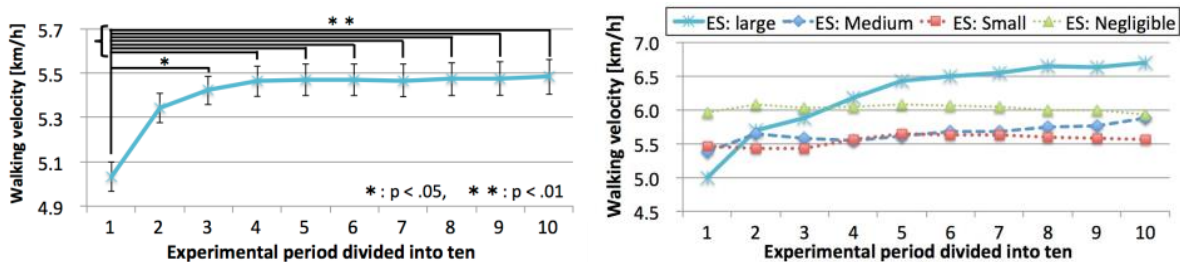

Fig. 5. Left: Change in mean walking velocity with change in the experimental period. The horizontal scale indicates the partial experimental period divided into 10 parts. The error bars represent standard error.

Right: Examples of change in walking velocity during the experimental period. The lines in the graph represent participants the changes in whose walking velocities were large, medium, small, and negligible in effect size (ES) calculated by Cohen's $d$. The horizontal scale represents the experimental period divided into 10 parts.

Table 1. Mean velocity change, walking distance, and walk days by effect sizes between walking velocities at $1 / 10$ th and $10 / 10$ th experimental periods.

\begin{tabular}{|c|c|c|c|c|}
\hline & \multicolumn{4}{|c|}{ Large Medium Small Negligible } \\
\hline Number of participants & 28 & 4 & 12 & 6 \\
\hline Ratio of mean velocity change & 1.15 & 1.08 & 1.02 & 1.01 \\
\hline Mean walk distance $[\mathrm{km}]$ & 11.6 & 9.1 & 12.6 & 10.3 \\
\hline Mean walk days & 58.8 & 55.5 & 59.7 & 49.6 \\
\hline
\end{tabular}

negligible. In Table 1, the mean walking distance and the number of days a walk was taken of a small effect group were the largest because some active seniors belonged to this group: a ceiling effect was observed because some of them had exercised regularly and had comparatively better performances than when the experiment had begun.

In the analysis of the correlation coefficient, no significant or interesting relationships were revealed among changes of walking velocity and number of walking days, and distance. Furthermore, we cannot confirm regular tendencies in the correlation coefficients representing changes in body fat percentage, body-mass index, the boundary length of the crus muscle, and access counts to the graph view page. It is true that the walking ability and health of most $(88.0 \%)$ participants improved, but the variation in these parameters was significant from one participant to another. The relationship between body conditions and walking ability should be investigated for a larger participant group.

\subsection{Difficulty in using our application interface, and design implications for seniors}

Most $(94 \%)$ of the participants reported that they could easily use our application because of its simple interface. According to the access log, these participants correctly uploaded their walk logs and checked their gait results. Three participants encountered difficulties with the small font size and the volume of the audio guide. According to their comments, they did not understand how to adjust the volume of the smartphone. Our future improvements will include increasing font size of the text in the application 


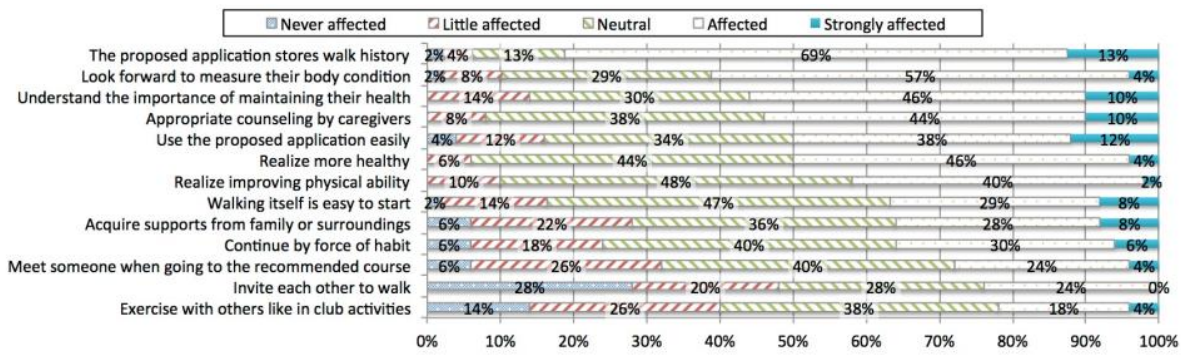

Fig. 6. Why participants would continue to walk regularly.

and writing an easier-to-read instruction manual. However, these three participants also successfully uploaded the sensor $\operatorname{logs}$ and browsed their gait results. Moreover, their walking days, distances, and velocity changes were almost identical to or greater than the average for the participants. This indicates that while the interface of our application presented a few complications, most seniors could easily use it.

Based on the lessons learned, the elements of application design should include appropriate font size and easily adjustable volume for the audio guide, support for applications, including easier-to-read instruction manuals for seniors, and a simple interface where most functions are accessible by explicit buttons.

\subsection{Why subjects would continue exercising}

According to Fig. 6, which shows participants'stated reasons for why they would continue walking regularly, over $80 \%$ of the participants said that the fact that the proposed application could store their walking history was the most significant motivator for continuing to walk regularly. According to participants' comments, the walking velocity, distance, and days were satisfactory motivators for them because these parameters were intuitively understandable. Some participants also indicated that they appreciated being able to check their walking distances and days because these parameters were the results of their efforts, and gave them a sense of accomplishment. Half of them reported that they would carry on walking because they looked forward to measuring their physical condition at the monthly meetings, understood the importance of maintaining their health, received appropriate counseling from caregivers, and could easily use the proposed application. Comparing changes in participants' walking velocities with the questionnaire responses, we saw no significant difference between groups of participants that had witnessed an improvement in walking velocity (large Cohen's $d$ ) and those that had not (small and negligible $d$ ) (Fisher's test, $p>.10$ ). Based on this result and that shown in the right part of Fig. 5, we conclude that our application can effectively help most seniors continue exercising.

Most participants regarded exercising with others as a club activity and inviting each other to walk as unnecessary for continuing to exercise. However, comparing changes in walking velocities with the corresponding responses to these social factors, participants who had significantly improved their walking velocities according to Cohen's $d$ reported positive effects in the questionnaire (Fisher's test, $p<.05$ ). The difference 


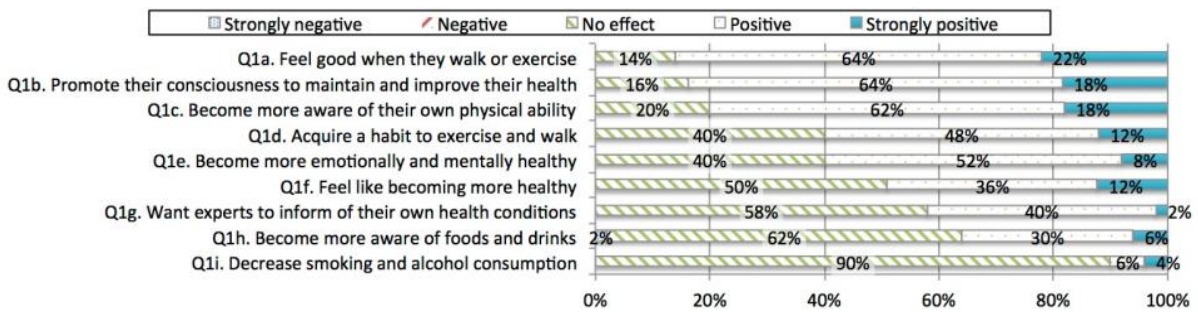

Fig. 7. The positive and negative effects of our application on participants' attitudes to their health.

in the tendency to answer thus did not depend on the initial walking velocity of the participants.

These results suggested that the appropriate motivators for seniors to walk regularly were the functions to store and present the details of the results of their exercise, whereas social factors, such as the pleasure of exercising with someone, did not attract all participants. However, seniors who were conscious of the benefits of social activity were motivated more by our application, regardless of their initial physical ability, including walking speed.

\subsection{Effects of the application on health management attitudes}

Figure 7 shows the contribution of our application to the positive and negative effects in terms of changes in the participants' attitudes to health consciousness. Over $80 \%$ of them indicated strong to moderately positive effects on health consciousness to continue regular exercise, maintain their health, and know their physical ability. Moreover, half of them reported having benefited by making a habit of walking, thus improving and maintaining their health. Comparing the improved and unimproved groups with regard to these items concerning health awareness, we found no significant differences (Fisher's test, $p>.10$ ) in any item. These results can suggest that the application contributed to raising participants' motivation to maintain and improve their physical fitness and health, and to exercise more regularly regardless of initial physical ability. However, participants who acquired a habit of walking as a result of the experiment mainly included those who did not regularly walk before. These results suggested that our application helps users improve the awareness of their health conditions and maintenances without depending on their exercise habit, and encourages seniors who do exercise regularly to continue to do so.

However, the application had little positive effect in terms of participants' awareness of nutrition, and with regard to reducing tobacco and alcohol consumption. This may have been the case in part because most participants did not smoke or drink much to begin with. A few participants reported ill effects, such as increased consumption of food and drink. A few participants gained weight during the course of the experiment, but the body fat percentage of most participants decreased or remained more or less unchanged. Therefore, our mobile application contributed positively to the seniors' awareness regarding their own health. 


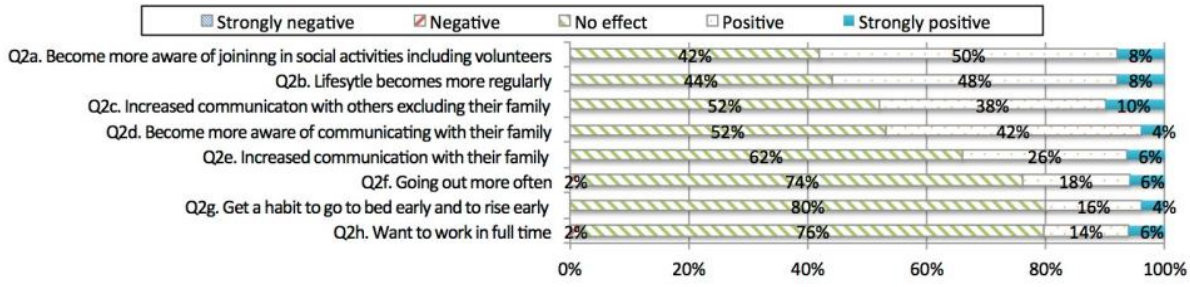

Fig. 8. The positive and negative effects of the application on participants' social activities.

\subsection{Effects on seniors' awareness of social activity and communication}

Figure 8 shows the positive and negative effects of the application on participants' awareness of social activities and communication with others. Approximately half the participants reported beneficial effects on their participation in social activities, including volunteering, acquiring well-regulated lifestyles, increased communication frequency with others excluding their families, and improved communication with their families. These results are interesting because the participants' initially reported motivation to walk, as shown in the right part of Fig. 2, concerned reflective characteristics: most of the seniors were not driven by social factors to take up the activity. According to the results of some statistical tests such as the $\chi^{2}$ tests and the analys is of variance (ANOVA), there were no significant differences in the tendency of these changes in social activity between the group of participants whose walking velocity had improved and one whose walking velocity had not. According to research in gerontology, the lifestyles of seniors can be explained by and classified into activity, disengagement, and continuity theories $[17,25,38]$. These spectra of aspects can perhaps be explained by seniors' exercise situation.

On the other hand, there was little positive effect with regard to increased outdoor activity among the participants, who got into the habit of going to sleep early and waking up early. This may be because most participants were healthy and regularly went outdoors. The results indicate that our application can encourage people to walk outdoors but cannot always activate their awareness to go outdoors.

However, a small number of the participants became more aware of full-time work as a consequence of using our application. Participants who reported positive effects on this item stated that they had wanted to work but had not been confident to do so full-time. On the contrary, participants who reported no effect with regard to this item said that they had retired from full-time work and were reluctant to do so again, or that they had been full-time homemakers thus far. The results indicate that the proposed application can influence seniors to participate more in volunteer activities, but can affect only prompt a few to go to work full-time.

\subsection{Effects on seniors' awareness of novel ICTs}

The positive and negative effects of our application on participants' awareness of ICTs are shown in Figure 9. Almost half reported being less resistant to new ICTs, including smartphones. Further, $40 \%$ said they wanted to learn more about smartphones. According to their comments, two participants had decided to s witch from a traditional feature 


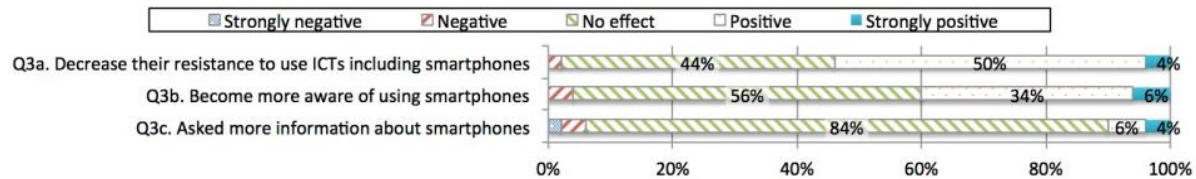

Fig. 9. The positive and negative effects of the application on participants' awareness of novel ICTs obtained through the application.

phone to a smartphone following this experiment. According to the results of Cohen's $d$, these two significantly improved their walking velocity during the course of the experiment. However, there was no significant difference in the preference for novel ICTs between the improved and unimproved groups in terms of walking velocity (Fisher's test, $p>.10$ ). On the whole, since they reported being more socially involved, including in volunteering activities, the proposed application can effectively contribute to increasing seniors' health awareness and affording them opportunities to participate in social activities.

Nevertheless, the participants had more negative comments on ICTs-related items than on any of the questions about health and social consciousness. Most of them had trouble using the proposed application. Some deleted the application by mistake, others forgot how to use it, and still others complained about the response time of the provided support. If we can provide better support for the application, these adverse effects can be mitigated. However, shortly after these issues, all participants became more skilled at negotiating our application with practice. To help seniors use support systems, it was important not only to develop senior-friendly interfaces, but also to organize an efficient service to solve their problems and teach them how to operate the application.

\subsection{Relations among changes in participants' awareness}

Fig. 10 shows the relations among participants' responses to the questionnaire items mentioned above. This path diagram was generated through structural equation modeling (SEM) using a correlation matrix of the answers. The diagram suggests that health consciousness and awareness of social activities are closely related, as are awareness of social activities and novel ICTs. Hence, it is no coincidence that our application encouraged seniors to walk outdoors more regularly, and that this led to an increase in participants' health consciousness, social activities, and rendered them more accepting of ICTs. In order to disseminate comprehensive support for ICTs in order to encourage physical activity among seniors, it can be effective to appeal to the functions of health maintenance and social participation.

\subsection{Limitations}

In our experiments, we restricted the area of walking measurements in order to ensure participants' privacy and physical safety, and to appropriately adjust the measurement conditions of the embedded sensors. This setting led to the situation where some participants met and affected a little each other. However, according to some participants' 


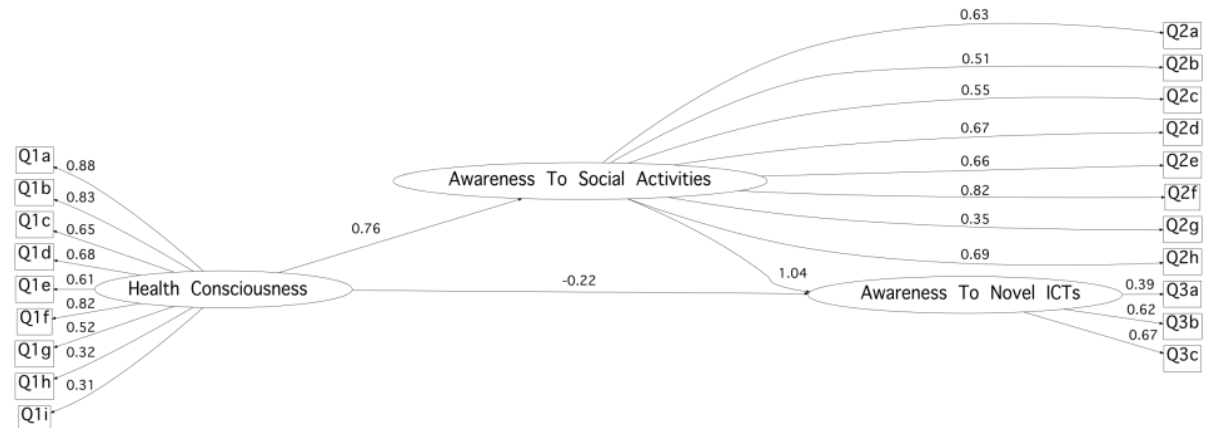

Fig. 10. Path diagram of awareness changes based on structural equation modeling. Sequential serial numbers "Qxx" correspond to the questionnaire items shown in Figs. 7, 8, and 9. The values are standardized solutions.

comments, they were not too bothered about privacy, and were willing to be tested in areas other than the course that was used. Following further analysis of the embedded sensors used for our application, we would like to conduct a similar study without the course limitation.

\section{Conclusion}

In order to help seniors maintain and improve their health and help theircaregivers monitor their physical condition, we implemented a mobile measurement system to record the details of their regular walking exercise using sensors embedded in smartphones, and then tested its usability and effects on seniors. The contributions of this paper can be summarized as follows:

- A walking-monitoring application that can operate on a smartphone and present the results of the exercise was developed, and a group of seniors was asked to use and assess it.

- The implemented application, using GPS sensors, can measure a user's walking distance and velocity with an accuracy of over $97 \%$ regardless of the time lags among the clocks of the devices and error in the horizontal accuracy.

- The application can motivate seniors to walk more because it presents them with their gait parameters, including walking velocity.

- The application has positive effects on health consciousness among seniors, who reported a resolve to continue exercising regularly in order to maintain their health and know their own physical ability.

- Half the participants reported being more socially aware and sociable, as well as being less resistant to novel ICTs as a result of using our application. This may be due to a successive "chain reaction" of awareness of health maintenance, social activities, and novel ICTs.

Our future work includes the following: 
- Further analyses of the effects of, and correlations among, the gait parameters, based on the calculation of acceleration and gyro sensors, on improvements in the physical parameters and lifestyle of seniors.

- Further analyses of the effects of course limitations on participants' exercise habits based on further experiments and meta-analysis of related work.

- Improvements in the proposed application, including the implementations of edit and record modes of the walking course, functions of indoor measurement, and more senior-friendly user interfaces.

\section{Acknowledgments}

This material is based on work funded by S-innovation (Strategic Promotion of Innovative Research and Development) funding under Industry Academia Collaborative R\&D Programs administered by the Japan Science and Technology Agency (JST). We are also grateful to the Healthcare Innovation Project (HIP) for their great help.

\section{References}

1. Apple iOS human interface guidelines. https://developer.apple.com/ library/ios/\#documentation/UserExperience/Conceptual/

MobileHIG/Introduction/Introduction.html

2. Bootstrap. http://getbootstrap.com/2.3.2/

3. FitBit one. https://www.fitbit.com/one

4. jqPlot charts and graphs for jquery. http://www.jqplot.com/

5. jQuery mobile. http://jquerymobile.com/

6. Nike+fuelband se. http://www.nike.com/us/en_us/c/nikeplus-fuelband

7. UP by Jawbone. https://jaw bone. com/u p

8. Al Mahmud, A., Key son, D.V.: Ubiquitous support for midwives to leverage daily activities. In: Proc. UbiComp '13 Adjunct, pp. 251-254. ACM, New York, NY, USA (2013)

9. Allet, L., Knols, R.H., Shirato, K., de Bruin, E.D.: Wearable systems for monitoring mobility-related activities in chronic disease: a systematic review. Sensors (Basel) 10(10), 9026-52 (2010)

10. Anderson, I., Maitland, J., Sherwood, S., Barkhuus, L., Chalmers, M., Hall, M., Brown, B., Muller, H.: Shakra: Tracking and sharing daily activity levels with unaugmented mobile phones. Mob. Netw. Appl. 12(2-3), 185-199 (Mar 2007)

11. Arai, T., Obuchi, S., Shiba, Y., Omuro, K., Nakano, C., Higashi, T.: The feasibility of measuring joint angular velocity with a gy ro-sensor. Arch Phy s Med Rehabil 89(1), 95-9 (2008)

12. Arnrich, B., Osmani, V., Riva, G., Bardram, J.: Ubihealth 2010: The 5th international workshop on ubiquitous health and wellness. In: Proc. Ubicomp '10 Adjunct, ACM, New York, USA. pp. 497-500. (2010)

13. Brajdic, A., Harle, R.: Walk detection and step counting on unconstrained smartphones. In: Proc. UbiComp '13, ACM, New York, NY, USA. pp. 225-234. (2013)

14. Cabinet Office: Annual report on the aging society 2013 (in Japanese). http://www8. cao.go.jp/kourei/whitepaper/w-2013/gaiyou/s1_1.html

15. Caine, K.E., Zimmerman, C.Y., Schall-Zimmerman, Z., Hazlewood, W.R., Sulgrove, A.C., Camp, L.J., Connelly, K.H., Huber, L.L., Shankar, K.: Digiswitch: Design and evaluation of a device for older adults to preserve privacy while monitoring health at home. In: Proc. IHI '10, ACM, New York, NY, USA. pp. 153-162. (2010) 
16. Chuah, M., Sample, S.: Fitness tour: A mobile application for combating obesity. In: Proc. MobileHealth '11, ACM, New York, NY, USA. pp. 9:1-9:5. (2011)

17. Cumming, E., Henry, W.E.: Growing Old: The Process of Disengagement. Basic Books (1961)

18. Earles, D.R., Judge, J.O., Gunnarsson, O.T.: Velocity training induces power-specific adaptations in highly functioning older adults. Arch Phys Med Rehabil 82(7), 872-8 (Jul 2001)

19. Fiatarone, M.A., Marks, E.C., Ry an, N.D., Meredith, C.N., Lipsitz, L.A., Evans, W.J.: Highintensity strength training in nonagenarians. effects on skeletal muscle. JAMA 263(22), 3029-34 (Jun 1990)

20. Fiatarone, M.A., O’Neill, E.F., Doyle, N., Clements, K.M., Roberts, S.B., Kehayias, J.J., Lipsitz, L.A., Evans, W.J.: The boston ficsit study: the effects of resistance training and nutritional supplementation on physical frailty in the oldest old. J Am Geriatr Soc 41(3), 333-7 (Mar 1993)

21. Fiatarone, M.A., O’Neill, E.F., Ryan, N.D., Clements, K.M., Solares, G.R., Nelson, M.E., Roberts, S.B., Kehayias, J.J., Lipsitz, L.A., Evans, W.J.: Exercise training and nutritional supplementation for physical frailty in very elderly people. N Engl J Med 330(25), 1769-75 (Jun 1994)

22. Hagler, S., Austin, D., Hay es, T.L., Kaye, J., Pavel, M.: Unobtrusive and ubiquitous in-home monitoring: A methodology for continuous assessment of gait velocity in elders. Biomedical Engineering, IEEE Transactions on 57(4), 813-820 (2010)

23. Hammerl, S., Hermann, T., Ritter, H.: Towards a semi-automatic personal digital diary: Detecting daily activities from smartphone sensors. In: Proc. PETRA '12, ACM, New York, USA. pp. 24:1-24:8. (2012)

24. Harris, T.J., Owen, C.G., Victor, C.R., Adams, R., Cook, D.G.: What factors are associated with physical activity in older people, assessed objectively by accelerometry? Br J Sports Med 43(6), 442-50 (Jun 2009)

25. Havighurst, R.J., Albrecht, R.E.: Older people. Arno Press (1980)

26. Hurling, R., Catt, M., Boni, M.D., Fairley, B.W., Hurst, T., Murray, P., Richardson, A., Sodhi, J.S.: Using internet and mobile phone technology to deliver an automated physical activity program: randomized controlled trial. J Med Internet Res 9(2), e7 (2007)

27. Inaba, Y., Obuchi, S., Arai, T., Satake, K., Takahira, N.: The long-term effects of progressive resistance training on health-related quality in older adults. J Phy siol Anthropol 27(2), 57-61 (Mar 2008)

28. Kaneko, R., Ishikawa, A., Ishii, F., Sasai, T., Iwasawa, M., Mita, F., Moriizumi, R.: Population projections for japan: 2006-2055 outline of results, methods, and assumptions. The Japanese Journal of Population 6(1), 76-114 (2008)

29. Kawarada, A., Takagi, T., Tsukada, A., Sasaki, K., Ishijima, M., Tamura, T., Togawa, T., Yamakoshi, K.: Evaluation of automated health monitoring system at the "welfare techno house". In: Proc. IEEE EMBC, 1998. . vol. 4, pp. 1984-1987. (1998)

30. Kay, M., Morris, D., schraefel, m., Kientz, J.A.: There's no such thing as gaining a pound: Reconsidering the bathroom scale user interface. In: Proc. UbiComp '13, ACM, New York, NY, USA. pp. 401-410. (2013)

31. Kientz, J.A., Patel, S.N., Jones, B., Price, E., My natt, E.D., Abowd, G.D.: The georgia tech aware home. In: CHI EA '08, ACM, New York, NY, USA, pp. 3675-3680. (2008)

32. Kobayashi, M., Hiyama, A., Miura, T., Asakawa, C., Hirose, M., Ifukube, T.: Elderly user evaluation of mobile touchscreen interactions. In: Proc. INTERACT 2011, pp. 83-99. Springer (2011)

33. Lepri, B., Mana, N., Cappelletti, A., Pianesi, F., Zancanaro, M.: What is happening now? detection of activities of daily living from simple visual features. Personal Ubiquitous Comput. 14(8), 749-766 (Dec 2010) 
34. Lin, R.J., Zhu, X.: Leverage user experience through social networking to improve health adherence. In: CHI '13 Extended Abstracts on Human Factors in Computing Sy stems. pp. 2341-2344. CHI EA '13, ACM, New York, NY, USA (2013)

35. Marie, C., Daniel, E., Eric, C.: Elderly daily activity habits or lifestyle in their natural environments. In: Proc. PETRA '11, ACM, New York, NY, USA. pp. 26:1-26:4. (2011)

36. Muramatsu, N., Akiyama, H.: Japan: Super-aging society preparing for the future. The Gerontologist 51(4), 425-432 (2011)

37. Nakajima, K., Anzai, E., Iwakami, Y., Saito, M., Ino, S., Ifukube, T., Yamashita, K., Ohta, Y.: Devel opment of the foot pressure measurement device and evaluation of ambulatory function for fall prevention on elderly. IEEJ MBE 60, 67-70 (2012)

38. Neugarten, B.L., Havighurst, R.J., Tobin, S.S.: Personality and patterns of aging. Robert J. Havighurst und et al.(Hg.): The meanings of age. Chicago [ua]: Univ. of Chicago Pr pp. 264-269 (1996)

39. Price, M.M., Pak, R., M ¥ ”uller, H., Stronge, A.: Older adults’ perceptions of usefulness of personal health records. Universal access in the information society 12(2), 191-204 (2013)

40. Sayers, S.P., Bean, J., Cuoco, A., LeBrasseur, N.K., Jette, A., Fielding, R.A.: Changes in function and disability after resistance training: does velocity matter?: a pilot study. Am J Phys Med Rehabil 82(8), 605-13 (Aug 2003)

41. Schuldhaus, D., Leutheuser, H., Eskofier, B.M.: Classification of daily life activities by decision level fusion of inertial sensor data. In: Proc. Body Nets '13, ICST, Brussels, Belgium, pp. 77-82 (2013)

42. Seiter, J., Feese, S., Arnrich, B., Trö ster, G., Amft, O., Macrea, L., Maurer, K.: Evaluating daily life activity using smartphones as novel outcome measure for surgical pain therapy. In: Proc. Body Nets '13, ICST, Brussels, Belgium, pp. 153-156 (2013)

43. Shimada, H., Obuchi, S., Furuna, T., Suzuki, T.: New intervention program for preventing falls among frail elderly people: the effects of perturbed walking exercise using a bilateral separated treadmill. Am J Phy s Med Rehabil 83(7), 493-9 (Jul 2004)

44. Siewiorek, D.: Generation smartphone. Spectrum, IEEE 49(9), 54-58 (2012)

45. Silva, P.A., Nunes, F., Vasconcelos, A., Kerwin, M., Moutinho, R., Teixeira, P.: Using the smartphone accelerometer to monitor fall risk while playing a game: The design and usability evaluation of dance! don't fall. In: Foundations of Augmented Cognition, pp. 754-763. Springer (2013)

46. Spina, G., Huang, G., Vaes, A., Spruit, M., Amft, O.: Copdtrainer: A smartphone-based motion rehabilitation training system with real-time acoustic feedback. In: Proc. UbiComp '13, ACM, New York, NY, USA. pp. 597-606. (2013)

47. Tamura, T., Kawarada, A., Nambu, M., Tsukada, A., Sasaki, K., Yamakoshi, K.I.: E-healthcare at an experimental welfare techno house in Japan. Open Med Inform J 1, 1-7 (2007)

48. Tanaka, T., Kojima, S., Takeda, H., Ino, S., Ifukube, T.: The influence of moving auditory stimuli on standing balance in healthy young adults and the elderly. Ergonomics 44(15), 1403-12 (Dec 2001)

49. Tsutsui, T., Muramatsu, N.: Japan's universal long-term care system reform of 2005: Containing costs and realizing a vision. J. Am. Geriatrics Soc. 55(9), 1458-63 (2007)

50. Yamashita, K., Iwasaki, Y., Imaizumi, K., Nakajima, S., Ino, S., Ifukube, T., Koyama, H., Kawasumi, M.: Evaluation of postural control of aging change by stabilogram diffusion analy sis. Journal of Life Support Engineering 20(1), 31-37 (2008) (in Japanese)

51. Yun, T.J., Arriaga, R.I.: A text message a day keeps the pulmonologist away. In: Proc. CHI '13, ACM, New York, NY, USA. pp. 1769-1778. (2013)

52. Zheng, Y., Li, Q., Chen, Y., Xie, X., Ma, W.Y.: Understanding mobility based on GPS data. In: Proc. UbiComp '08, ACM, New York, NY, USA. pp. 312-321. (2008),

53. Zickuhr, K., Madden, M.: Older adults and internet use. Pew Internet \& American Life Project (2012) 